\title{
The Influence of Organizational Culture on
}

\section{Organizational Learning, Worker Involvement}

\author{
and Worker Productivity
}

\author{
Kodjo Ezane Joseph (Corresponding author) \& Changjun Dai \\ Glorious Sun School of Business and Management \\ 1882 Yan'an West Road, Donghua University \\ Shanghai 200051, China
}

Tel: 86-15021330844Ｅ-mail: kodjo_ezane@yahoo.fr

\begin{abstract}
The objective of this study is to investigate the probable correspondence among organizational culture, organizational learning, and worker involvement and worker productivity. The author investigated 40 enterprises and 4 structured questionnaires were distributed within enterprises to be filled out. This resulted in 160 responses. There were 63 organizations selected for this study, but only 40 showed interest and participated in the research representing about a $63.49 \%$ response rate of the collection of data that we found important for a developing economy like Ivory Coast. A relational research design and a descriptive analysis were utilized to appreciate the correlation amongst the variables. The findings of this study revealed that there are significant correlations amongst the different variables.
\end{abstract}

Keywords: Human resource management, Organizational performance, Knowledge management, Work environment, Abidjan (Ivory Coast)

\section{Introduction}

People give sense and meaning to organizations because they are undoubtedly capable of giving to any organization, direction, that is, leadership, competitiveness, and organizational performance. Employees know how to push the organization for a better challenge in this turbulent and up-and-coming business environment. Employees can and should be part of the journey in giving to organizations, the potentials to meet up their customers' demands and their unambiguous and affirmed objectives or goals. Human resources (HRs) can continuously acquire new habits and productive ideas to be of assistance for organizations to change their organizations' status, that is, from bad performance to good one. People are as we know the organizations' most pertinent resource and the power (force) of the organizations is their people as well. In any sort of organizations, things are made possible or things happen thanks to people.

In the Ivorian setting, the motivation of employees is more and more becoming a genuine problem in the management of HRs. An organization centers its attention more on the development of its business systems rather than on the motivation of its internal customers to pull off important business performance. Amazing as this might be in this era of information-based economy (IBE), that is, knowledge management (KM), today's organizations (not all of them) in Ivory Coast are not realizing that the valuable management of HRs, a good environment and employee motivation are conditions for the fulfillment and well-being of customers in this $21^{\text {st }}$ ever-increasing aggressive (competitive) global market. Organizational culture is a main element for promoting an innovative environment. The organization's culture represents the process of the way things are done. Corporate culture is the core factor, but it must also fit with the structure of organization, the management of employees, leadership style, and knowledge strategy systems (Forcadell \& Guadillas, 2002).

The objective of this current work is to investigate the likely correspondence among the ensuing variables: Organizational culture, Organizational learning, and worker involvement and worker productivity in the Ivorian context as a stimulating and energized work environment motivates employees to use the potential that resides in them to 
organizational performance. But also, provide recommendations to top management in Ivory Coast about the importance of providing a good, innovative work environment for employees to be productive.

\section{Literature Review and Hypotheses}

\subsection{Organizational Culture}

Organizational culture is a main element for promoting an innovative environment. The organization's culture represents the process of the way things are done. Corporate culture is the core factor, but it must also fit with the structure of organization, the management of employees, leadership style, and knowledge strategy systems (Forcadell \& Guadillas, 2002). Tidd et al. (2001) hold that since many process innovations represent major changes in "the way we do things around here", the question of managing cultural change and overcoming resistance to innovation needs to be addressed.

There is a human element in the culture of an organization that cannot be left out and is the determinant in effective business performance and management of change. Moffert et al. (2002) observe that to change an organization's culture, peoples' values, norms and attitudes must be amended so that they make the right contribution to the collective culture of the organization. The right contribution is necessary because too drastic of a shift can affect the organized behavior or the established routines in very negative ways. Another aspect that must be understood is that each organization requires a different set of cultural values. If an organization is dealing with ambiguous situations that require a variety of insights, then there is a higher need for flexibility.

\subsection{Organizational Learning}

A culture must be established that enables each organization to operate within its knowledge demands. What must be emphasized here is that each enterprise has a different environment that requires specialization. Tidd et al. (2001) indicate that culture is an artifact of what people believe and how they behave; if there is a good fit, it will enable and reinforce innovative behavior. If it is contradictory to these beliefs for instance, restricting communication, stressing hierarchy - then it is likely to act as a brake on creativity and innovation.

Actually, if an organization's culture is centered on learning, and its structure is such that the actors within the organization can transmit knowledge, then human resources are more likely to feel empowered to learn. It is important for an enterprise to establish an environment that is apt to create and renovate its knowledge to keep pace with innovation. A knowledge-oriented culture challenges people to share knowledge throughout the organization. An organization can promote and reinforce an environment that enables learning, and hence leads to innovative capacities, through its cultural framework. The way this is done is going to be determined by the makeup and management style of each organization. Each organization has its own set of variables that must be taken into account.

Establishing a learning culture (LC) is going to require a different process and procedure to match the criteria. The management can promote its organization as a learning establishment and develop cultural norms that mitigate this cause. However, the establishment of a LC is not enough. Organizations must regenerate the emphasis through changing times. Another part of the establishment of the firm as a learning organization is the fact that it must be ubiquitous. That is, the culture of learning today within enterprises established and operating in Ivory Coast should seek for managerial employees and non-managerial employees' inputs. From the on-going arguments, we propose the ensuing:

\section{H1: Organizational culture positively impacts organizational learning.}

\subsection{Worker Involvement}

The term worker involvement (WI) is used to indicate that these initiatives were largely those designed and introduced by management and intended to improve communications with employees, to generate greater commitment, and enhance employee contributions to the organizations (Marchington, May 1992). Solomom (1998, third edition) observes that the nature of the relationship between employees and management in the organizations decision-making process is central to the character and conduct of the industrial relations system at the organizational level. Employee involvement (EI) or motivation assists an organization to give the best possible service to customers and clients in the most cost-effective way, it entails providing employees with the opportunity to influence and where appropriate, take part in the decision-making on matters which affect them, it is an intrinsic part of good management practice and is therefore not confined to relationships with employee representatives, and finally it can only be developed voluntarily and in ways suited to the activities, structure, and history of an organization (CBI, 1979).

Farnham (1993) holds that EI promotes business success. It does this by fostering trust and a shared commitment to an organization's objectives, demonstrating respect for individual employees and enabling employees to get maximum job satisfaction. Employees are the main targets of any participation scheme adopted by managers. And employees know this; they also feel that management use this type of participation for greater efficiency, performance and productivity. 
On the other hand employers believe in the potential benefits that can be gained from a motivated worker. As a result of the discussion above, we propose that:

H2: Organizational culture positively impacts worker involvement.

\subsection{Worker Productivity}

Employers, regardless of what type of business they manage, know that worker productivity (WP) is the key to an organization's success. Workers who are not using their time and resources effectively are costing the company money. Miller and Monge (1986) hold that job satisfaction increases output through bringing high quality stimulus and through increasing working capabilities at time of implementation. Employees want to do the right thing and they will do so if they have the right information. Focusing on capturing timely and accurate information and sharing it with whomever needs it to do their job bring about employee productivity. Today, to compete in this turbulent business environment, organizations should be empowering their employees to quickly notify quality, production, materials management, and maintenance personnel of potential problems before adversely affecting plant operations. Communication solutions should ensure speedy and effective supervision of the ever-changing requirements of a dynamic organization operation. Visual feedback provides employees real-time updates on how they are progressing relative to daily goals. Studies (see for example, O'Relly \& Pfeffer, 2002) indicate that human resource policies (HRP) that give confidence to employee involvement aim at providing employees with opportunities to have a participation in decisions, incentives to expend discretionary effort and the means to acquire the suitable skills.

In relation to the HRP (see for instance, O'Relly \& Pfeffer, 2002), participation schemes directly affect the first two aspects - opportunities and incentives - and as a result are thought to improve incentives to acquire skills as well as work organization and information flows. These combined effects are expected to increase X-efficiency and productivity (Komal \& Tahir, 2007). The primary goal of HRM in any organization is to facilitate organizational performance (OP). Poor performance can result from any causes, such as inability to manage, failure to prioritize, lack of skill, knowledge, or motivation and changes in performance management systems or process. However, one of the most effective ways of enhancing OP is by increasing productivity, that is, the efficiency allowing an organization to use its labor, capital, material, and energy resources to produce its output. This will bring us to test the following hypothesis:

H3: Organizational culture positively impacts worker productivity.

\section{Research Design}

\subsection{Research approach}

A research approach was utilized for the objective of this current research study to determine how to get the required data for analysis. This study consisted of two categories of employees: managerial employees and non-managerial employees who responded in filling out the questionnaires given to them within their respective organizations in Abidjan, Capital city of Ivory Coast from February $7^{\text {th }}, 2007$ to August $29^{\text {th }}, 2007$.

\subsection{Research strategy}

In this study, it was very interesting and important to find out what the research inquiry was about. While considering the postulations, it became clear that the study was exploratory. The theory was firmly based and explained; it was then important to determine how, why these theories were used. Silverman (1993) holds that there must be a methodology (a general approach to studying research topic), and a method (a specific research technique). It was then important to analyze the data collected within the organizations in order to understand how things happen the way that they do. This study aligns itself with the relational canon. In Mark's (2002), Van Maanen (1983) defines qualitative techniques as 'an array of interpretative techniques which seek to describe, decode, translate and otherwise come to terms with the meaning, not the frequency, of certain more or less naturally occurring phenomena in the social world'. The research dwells on a set of explanatory concepts (Theory); propositions that can be tested (Hypothesis); a methodology. This study was set upon these same basic guidelines.

\subsection{Research method}

This research uses relational analysis and statistics through structured questionnaires for exploring the correlation amongst the identified variables (OC; OL; WI; WP). The researcher first designed the data gathering method and secondly found a way of analyzing them for reasonable conclusions drawing as hypotheses were to be tested.

\subsubsection{Data gathering}

\subsubsection{Population and sampling}

The respondents were classified as managerial employees and non-managerial employees. The managerial employees are those whose work consists mainly of directing and supervising the work of others on the employer's behalf. The managerial employees were the human resource managers (20). The non-managerial employees are those who perform 
tasks not involving the direction and control of enterprise activity. The non-managerial employees were the production workers (20).

\subsection{Structured questionnaires}

To reach our objective, data was collected through four (4) questionnaires distributed within the organizations. The questionnaires were easily laid out to be completed considering the principles announced by Mark et al. (2002) namely: The clearance of the questionnaires; the avoidance of any jargon or specialist language; and the avoidance of personal questions. The 4 structured questionnaires centered on organizational culture (dependent variable) and the independent variables (learning within the organizations; employee motivation and employee performance) to investigate the correlation among them. The respondents were simply asked to select between 1 and 5 , where " 1 " means "strongly disagree" and "5" means "strongly agree". Studies (see for example Wright et al., 1999; Ngo et al., 1998) utilized that kind of likert scale. This gave the researcher a total number of 160 responses.

\subsection{Threat to credibility}

The participants were reluctant to fill out the questionnaires. Assurance of anonymity was accepted. All the participants were willing to participate in the research. The researcher distributed the questionnaires. They provided written comments (responses) on a timely basis. All the participants showed interest in the research as they emphasized its importance.

\subsubsection{Data analysis}

We coded and continuously analyzed the data that was collected. The collection of data permitted to numerically code the responses given by the participants to make the data actionable. We hypothesized that organizational culture positively impacts organizational learning. The importance of a good working environment (organizational culture) is a driver for organizational learning; that worker involvement is also influenced by organizational culture; that worker productivity is positively influenced by organizational culture. The hypothetical research model (see figure 1) needed to be tested. The different hypotheses were tested through correlation, regression analyses, and a linear regression model. Therefore, we used the commercial software package for social sciences (SPSS, Version 11.0) for data coding and data analysis. The hypothetical research model and the identified variables for this investigation are revealed in figure 1.

\section{(Insert Figure 1 about here)}

\section{Findings}

Table 1 presents the descriptive statistics results in terms of mean, standard deviations and correlations for the different variables used in the research model.

(Insert Table 1 about here)

Table 1 indicates that there is a significant correlation between the explanatory variables, that is, the independent variables (organizational learning, worker involvement, worker productivity and the dependent variable (organizational culture). Mean for worker productivity (WP) is 4.85 , whereas, the standard deviation (SD) is 2.3 . This result shows that the contribution and the technological level of the employees are substantial. A positive correlation between WP $(0.422)$ and organizational culture $(\mathrm{OC})$ indicates that $\mathrm{OC}$ is a significant factor for organizational performance. This result is confirmed by O' Relly et al. (2000) as they hold that culture and environment are the good predictors of employees' success as a good culture and a good working environment requires that organization have the following: encourage fun in the workplace; create a good physical place to work including needed resources to do the job right; establish a mentoring program; actively promote positive relationship among co-workers; build an atmosphere of trust and fairness; and put employees on the organizations' balance sheet, to make them an essential part of the organizations' community - an inclusive, extended-family relationship. Furthermore, organizational culture is positively impacted (correlated) by worker involvement (0.343), organizational learning (0.186). Consequently, the importance of a good atmosphere within an organization as organizations that have respect for their employees give them a reason for being by engendering pride and commitment through the organization's culture that helps employees understand the organization's mission statement, vision, values, and how these apply to their day-to-day working hours will be competitive. Employees should be enthusiastic as stimulating and rewarding work environment give stimulus to employees who are motivated and dedicated for organizations to have a competitive advantage. The researcher notices a negative correlation that exists between worker turnover and the following: organizational culture $(-0.212)$; organizational learning $(-0.270)$; worker involvement $(-0.179)$; and worker productivity $(-0.042)$. This shows that the culture and environment of an organization have a considerable impact on the performance or productivity of a worker; the motivation of workers to learn; to acquire new tools and up-date their initial and professional training.

In order to achieve great endeavors, organizations in Abidjan (Ivory Coast) must for example importantly celebrate what is going on right within the organization on a frequent basis. They should also encourage positive work relations through team-building and training; and get employees at all levels involved in plans and executing celebrations of all 
kinds. Organizations that are compassionate, get honest with employees are those that will be hard to leave. Recognized as valued assets of organizations, corporate culture should be managed so as to make it compatible with the requirements of corporate strategy (Beer \& Spector, 1985) to key business performance drivers such as productivity, innovation and customer satisfaction.

Because human resources are "ingredients" of success for firms, investment in the management of human resources should be effective and efficient. Employees as we know are organizations' most significant resource. Therefore, due meaning should be attached to human resource management (HRM). Good HRM should be the top priority to top management. As employee motivation and implication are fundamental for capacity building, special attention should be paid to the employees' competence and motivation. Employees being at the heart of organizations, employee satisfaction should be monitored through regular employee surveys to know about their likes and dislikes to avoid employee turnover that can be costly for the organizations and disrupt work.

The findings indicate that there are noteworthy interrelationships amongst organizational culture, worker involvement, and worker productivity; that the management of human resources within enterprises requires that top management create, maintain and develop efficient organizations for them to be competitive as learning organizations can succeed in the future, and the "well-being" organizations can have employees who will be motivated and have the energy to work in the long run. To test our specific propositions, regression analysis was used through the following model:

$$
O C_{i}=\beta_{0}+\beta_{1} O L_{i}+\beta_{2} W I_{i}+\beta_{3} W P_{i}+\zeta_{i}
$$

Where

The different $\beta_{i}$ represent the parameters to be estimated. (i) represents the characteristic of the enterprise surveyed; its value varies between 1 and 40 corresponding to the number of the enterprises. The variables are identified like the ones done previously. $\zeta$ is the random error. It contains all the other variables that are not taken into account by the model. The regression results are presented in Table 2 .

\section{(Insert Table 2 about Here)}

Table 2 highlights the regression results of the model for testing the different propositions that this research reveals. From the findings in the table under study, the variables "organizational culture" with a coefficient of 0.255 and a standard deviation (SD) of 4.74; "worker involvement" (0.497) and a 4.77 SD; "employee productivity" with a coefficient of 2.068 and a SD of 4.85 show that important correspondence is effective amongst the diverse variables acknowledged for the scope of this inquiry. As a result, the level of significance for the identified variables that is, organizational learning $\left(0.045^{*}\right)$; worker involvement $\left(0.059^{*}\right)$; and employee productivity $\left(0.166^{* *}\right)$ also corroborates the effectiveness and the importance of relationship along with the different variables. With $\mathrm{R}^{2}$ being 0.79 , that is $79 \%$ and Adjusted $\mathrm{R}^{2}$ of 0.75 , it was indicated that the regression model was important as all the variables were statistically important. The hypothetical research model for this research inquiry can be built up consistent with the results obtained in figure 2 .

\section{(Insert Figure 2 about here)}

Figure 2 reveals the research model of this study and the findings of the regression analysis. Figure 2 shows a confirmation that our different hypotheses are verified as correlations really exist amid organizational culture and organizational learning $(+0.255)$; worker involvement $(+0.497)$; and finally, worker productivity $(+2.068)$. These results also indicate that corporate culture is a driver for organizations in Ivory Coast to make organizational learning effective for employee to be competitive to boost organizational performance. An organization that does not encourage organizational learning cannot be an intelligent organization as intelligent organizations are those who know that "knowledge is power". For employees (managerial workers and non-managerial workers) to be motivated and productive for the organizations that they work for in Ivory Coast, those organizations need to have a good corporate culture that gives energy to the system as a good working environment is a source of employee motivation that can move the organizations in Ivory Coast from mediocrity to excellence.

\section{Conclusion}

The scope of this paper was to try to investigate and understand the link that exists among the ensuing variables: organizational culture (dependent variable); organizational learning; worker involvement; and worker productivity as independent variables. We have presented the empirical tests of organizational culture; organizational learning; worker involvement (motivation) and employee productivity in 40 enterprises of different structures established and operating in Abidjan, Ivory Coast. To reach this goal, we used a relational research design and a descriptive analysis method to establish the correlation between the variables indicated earlier. The results are revealed in Table 1 and Table 2 . Table 1 provides positive correlations amongst all the variables. Table 2 highlights the regression results of the linear model where the variable explained "organizational culture" shows some precisions on the nature and the degree of existing correlations. 
The findings of this research reveal that organizational culture impacts organizational learning, employee motivation and employee productivity. These findings also indicate that in today's labor market, organizations need to meet a new set of employee expectation. A stimulating and rewarding work environment is key element in the equation. Consequently, there is a need for human resources to understand and feel part of organizations, and how to know their individual role contributes to the organizations as a whole. For employees in Abidjan, Ivory Coast to be productive, they need to work in an environment that energizes and stimulates. Creating a positive environment is not easy. Communication, motivating and leading people are difficult as well. Because those things mentioned above are not an easy task, organizations in Abidjan should communicate creatively by honestly sharing important information through open forums and state of organizations' meeting; keep in touch with employees without any discrimination, favoritism, nepotism at all levels through face-to face interactions; offer constant informal feedback; make expectations clear; seek employees' inputs in job-related issues. Effective communication contributes to a healthy cooperative work environment. Establishing a good organizational culture characterized by cooperation between groups, employee involvement, and active participation, trustfulness in people, open communication and information as well as empowerment are conducive to organizational performance. An organization's ability to learn and translate that learning into action rapidly is the ultimate competitive advantage. As knowledge management starts with business objectives and processes and recognition of the need to share information, business leaders in Abidjan, Ivory Coast need to establish an atmosphere that encourages collaboration and knowledge sharing.

For organizations in Ivory Coast to be efficient and healthy, they need to be able to renew themselves continuously and to foresee changes. Organizational learning is faster than the changes in the environment and this is why it is apt to manage change. As employees are their most significant resource, that resource should be structured to pay close attention to their well-being. Pettini (2002) observes that we should build organizations for people, not adapt people to organizations. We should have a vision about our work communities too. We spend the best part of our lives in different organizations. We should make these organizations ideal places to work in, be together and grow comprehensively as human beings. Our findings bring us to have a couple of suggestions that are apt to bring organizations established and operating in Abidjan to motivate employees to use the potential that resides in them to organizational performance. As motivation is one of the easiest concepts to understand, yet one of the most difficult to implement, this paper suggests that in order to motivate and retain employees, organizations in Abidjan should communicate creatively; establish a stimulating culture and environment; have respect for employees to keep them motivated and productive. They should give employee a reason for being in allowing them to understand the organization's mission statement, vision and values to name just a few. Organizations in Ivory Coast that are able to provide these key factors will get skillful and honest employees who will work toward the organization's goals and objectives.

All researches are conducted with certain limitations. The current research is no exception. Firstly, though questionnaire technique has been utilized for this study, group discussions could have been utilized as well. Secondly, the sample size is small $(\mathrm{N}=160)$. This is not sufficient enough to reflect the sound picture of the enterprises established and operating in the whole country (Ivory Coast) in the context of establishing the correlation among organizational culture (OC), organizational learning (OL), and worker involvement (WI) and worker productivity (WP). Therefore, there should be a longitudinal study and more sophisticated measures of OC all through the country for a much more significant assessment of the relationships among OC; OL; WI; and WP in Ivory Coast. Despite these limitations, the statistical findings of this research inquiry provide a new piece in the jigsaw of the management of human resources in enterprises in Abidjan, Ivory Coast. The evidence supports the conclusions that organizational culture significantly influences organizational learning; employee motivation; and employee productivity.

\section{References}

Beer M \& Spector, Lawrence P, Millis, D \& Walton. (1985). HRM: A General Manager's Perspective, New York: Free Press.

CBI. (1979). Priorities for in-company communications: A corporate appraisal Report No.770, The Conference Board.

Farnham A, D. (1993). Employee Relations, Exeter: Short Run Press. Knowledge and Process Management, 9 (3): 162-171.

Forcadell, Francisco J. \& Guadamillas, Fa'tima. (2002). A case Study on the Implementation of a Knowledge Management Strategy Oriented to Innovation. Knowledge Management and Process, 9 (3): 1962-171.

Komal K. B \& Tahir M. Q. (2007). Impact of Employee Participation on Job Satisfaction, Employee Commitment and Employee Productivity. International Review of Business Research Papers, Vol. 3, No.2 June 2007, pp. 54-68.

Littman, Margaret. (2000). Best Boss tell All. Working Women, Oct. p. 51.

Marchington, M., Goodman, J. et al. (1992). New Development in Employee Involvement Department of Employment Research, Series No. 2 
Mark Easterby, Smith Richard Thorpe, \& Andy Lowe. (2002). Management Research: An Introduction (2 ${ }^{\text {nd }}$ Ed.), London, Sage Publications.

Miller K.I \& Monge, P.R. (1986). Participation, Satisfaction and Productivity: A Meta-Analytical Review. Academy of Management Journal, Vol. 29, No. 4, pp. 727-753.

Moffert, Sandra \& McAdam, Rodney \& Parkinson,Stephen. (2002). Developing a Model for Technology \& Cultural Factors in Knowledge Management: A Factor Analysis. Knowledge and Process Management, 9 (4): $237-255$.

Ngo, Hang-Yue, Daniel Turban, Chung-Ming Lan, and Siu-Yun Lui. (1998). HRM practices and firm performance of multinational Corporations: Influences of country of origin. Journal of International Management, 9:632-652.

O'Relly, Charles A, \& Jeffrey Pfeffer. (2002). Hidden Value: Hoe great Companies Achieve Extraordinary results with Ordinary People, Boston, MA, Harvard Business School Press.

Pettini, S. (2002). An Intelligent Organization: Integrating performance and Knowledge Management, Capstone Publishing Limited (a Wiley Company).

Salomom, M. (1998; third edition). Industrial Relations, London: Prentice Hall.

Siverman D. (1993). Interpreting qualitative Data: Methods for Analyzing Talk, Text and Interaction, London: Sage.

Tidd, Joe \& Bessant, \& Pavitt, Kerth. (2001). Managing Innovation: Integrating Technological, Market and Organizational Change, Wiley.

Van Maamen, J . (1988). Tales of the Field, Chicago: University of Chicago Press.

Wagner, A.J. (1994). Participation's effects on performance and satisfaction: A reconsideration of research evidence. Academy of Management Review, Vol. 19, pp. 312-330.

Wright Patrick M., Blaine McCormick, Scott Sherman, \& Gary C. McMahan. (1999). The role of human resource practices in petro-chemical refinery performance. International Journal of Human Resource Management, 10: $551-571$.

Table 1. Means and correlations of variables

\begin{tabular}{|c|c|c|c|c|c|c|}
\hline & Standard Deviation & Mean & OC & OL & WI & WP \\
\hline Organizational Culture & 1.4 & 4.46 & 1.000 & 0.186 & 0.343 & 0.422 \\
Organizational Learning & 1.1 & 4.74 & 0.186 & 1.000 & 0.034 & 0.322 \\
Worker Involvement & 1.8 & 4.77 & 0.343 & 0.034 & 1.000 & 0.167 \\
Worker Productivity & 2.3 & 4.85 & 0.422 & 0.322 & 0.167 & 1.000 \\
Worker Turnover & 1.3 & 3.44 & -0.212 & -0.270 & -0.179 & -0.042 \\
\hline Organizational Performance & 1.2 & 4.24 & 0.145 & 0.317 & 0.128 & 0.451 \\
\hline
\end{tabular}

Where as:

OC: Organizational Culture; OL: Organizational Learning; WI: Worker Involvement; WP: Worker Productivity; WT: Worker Turnover; OP: Organizational Performance

Table 2. Regression results of model

\begin{tabular}{|c|c|c|c|c|c|c|}
\hline & Coefficient & $\begin{array}{c}\text { Standard } \\
\text { Deviation }\end{array}$ & $\mathrm{t}$ & $\mathrm{P}>$ ItI & \multicolumn{2}{c|}{$\begin{array}{c}\text { Interval } \\
\text { Conf. }\end{array}$} \\
\hline Organizational Learning & 0.255 & 4.74 & 0.328 & $0.045^{*}$ & 0.174 & 0.349 \\
Worker Involvement & 0.497 & 4.77 & 0.483 & $0.059^{*}$ & 0.921 & 2.015 \\
Employee Productivity & 2.068 & 4.85 & 0.211 & $0.166^{* *}$ & 1.490 & 3.293 \\
$\mathrm{R}^{2}$ & 0.79 & & & & & \\
\hline Adjusted $\mathrm{R}^{2}$ & 0.75 & \multicolumn{5}{|c|}{$\mathrm{F}=32.16$} \\
\hline
\end{tabular}

Note: $\mathrm{N}=160,{ }^{*} \mathrm{p}<0.05, * * \mathrm{p}<0.1$ 


\section{Organizational Culture}

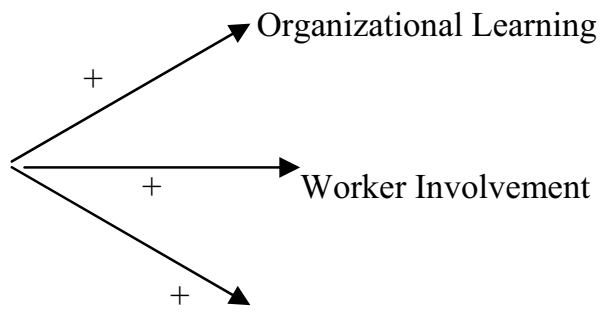

Worker Productivity

Figure 1. Hypothetical research model and variables

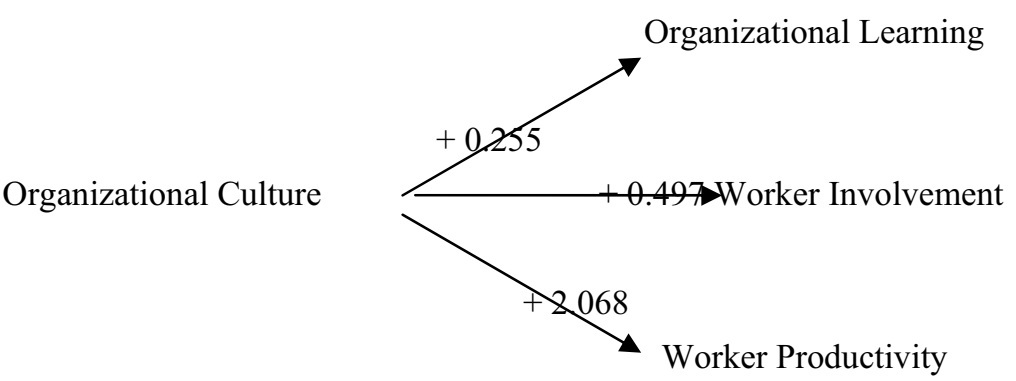

Figure 2. Research model with regression outcomes 